\title{
O LÚDICO: JOGOS, BRINCADEIRAS E A CONSTRUÇÃO DO PROCESSO DE APRENDIZAGEM NAS SÉRIES INICIAIS DO ENSINO INFANTIL
}

Aparecida Dias de Macedo ${ }^{1}$

Ariane Delprete Faria ${ }^{2}$

\section{RESUMO}

Este artigo exibe as principais reflexões analíticas a partir de diferentes autores sobre o verdadeiro conceito de lúdico na área da educação. Busca-se trazer a temática do lúdico, refletindo o seu impacto para crianças a partir de 5 anos de idade, e que fazem parte da rede de ensino infantil. A importância do lúdico, para elas, não é somente a atividade ou a brincadeira de forma liberta, prazerosa, mas o foco em sua aplicabilidade e conexão com os conteúdos dispostos na sala de aula também. Por meio de pesquisa bibliográfica, onde cria-se uma reflexão analítica de diversos pontos de vistas diferentes sobre o mesmo tema, este trabalho tem por objetivo compreender e aprofundar o conceito de lúdico como uma estratégia para o desenvolvimento do ensino aprendizagem na área da educação. Dessa forma, buscou-se entender como este conceito pode auxiliar diretamente no ensino dos alunos no ambiente escolar, bem como entender como ele pode facilitar a atuação do professor para que o processo de ensino/aprendizagem seja cada vez mais eficiente e prazeroso, tanto para o aluno quanto para aquele que leciona. O ensino lúdico é, comprovadamente por diversos autores, uma estratégia positiva e eficaz para a aprendizagem infantil. A escola deve resguardar de todas as formas o direito de brincar das crianças, buscando a ludicidade natural do indivíduo. Concluiu-se que os professores não utilizam o ensino lúdico no país em sua real e total potencialidade, o que corrobora negativamente para o ensino infantil em nosso país.

Palavras-chave: Lúdico. Educação. Ensino/aprendizagem

\begin{abstract}
This article presents the main analytical reflections from different authors about the true concept of playfulness in the area of education. It seeks to bring the theme of the playful, reflecting its impact to children from 5 years of age, and who are part of the children's

\footnotetext{
${ }^{1}$ Graduada em Licenciatura Plena em Matemática pela Faculdade de Filosofia, Ciências e Letras de Alegre_ES, Licenciatura Plena em Geografia pela Universidade Metropolitana de Santos, especialista Lato sensu em Educação Especial e Matemática pela Faculdades Integradas de Jacarepaguá, especialista Lato sensu em Gestão Escolar Integradora: S.E; O.E; I.E; pela Universidade Castelo Branco, aluna do curso de Mestrado Scricto Sensu pelo Facultad Interamericana de Cièncias Sociales- FICS, atua como professora na rede municipal de Muniz Freire_ES.

${ }^{2}$ Graduada em Licenciatura Plena em Ciências Biológicas pela Faculdade de Filosofia, Ciências e Letras de Alegre, especialista Lato sensu em Educação Ambiental e Recursos Naturais pela Faculdade de Ciências e Letras de Alegre, especialista em Ciências Biológicas pela Faculdade do Noroeste de Minas (FINOM), aluna do curso de Mestrado Scricto Sensu pelo Institute of Tecnology Education e Health, atua como professora na rede municipal de Muniz Freire-ES.
} 
education network. The importance of the playfulness for them is not only the activity or the play in a free, pleasurable way, but the focus on their applicability and connection with the contents arranged in the classroom as well. Through a bibliographical research, which creates an analytical reflection of different points of view on the same theme, this work aims to understand and deepen the concept of play as a strategy for the development of teaching learning in the area of education. In this way, it was sought to understand how this concept can directly aid the teaching of students in the school environment, as well as to understand how it can facilitate the performance of the teacher so that the teaching / learning process is more efficient and pleasurable both for the student as well as the learner. The playful teaching is, evidently by several authors, a positive and effective strategy for children's learning. The school must safeguard in all its forms the right to play with children, seeking the natural playfulness of the individual. It was concluded that teachers do not use playful education in the country in its real and total potential, which corroborates negatively to the teaching of children in our country.

Keywords: Playful. Education. Teaching/learning.

\section{RESUMEN}

Este artículo muestra las principales reflexiones analíticas a partir de diferentes autores sobre el verdadero concepto de lúdico en el área de la educación. Se busca traer la temática del lúdico, reflejando su impacto para niños a partir de 5 años de edad, y que forman parte de la red de enseñanza infantil. La importancia del lúdico, para ellas, no es solamente la actividad o el juego de forma liberada, placentera, sino el foco en su aplicabilidad y conexión con los contenidos dispuestos en el aula también. Por medio de la investigación bibliográfica, donde se crea una reflexión analítica de diversos puntos de vista diferentes sobre el mismo tema, este trabajo tiene por objetivo comprender y profundizar el concepto de lúdico como una estrategia para el desarrollo de la enseñanza aprendizaje en el área de la educación. De esta forma, se buscó entender cómo este concepto puede auxiliar directamente en la enseñanza de los alumnos en el ambiente escolar, así como entender cómo puede facilitar la actuación del profesor para que el proceso de enseñanza / aprendizaje sea cada vez más eficiente y placentero, tanto para el alumno como para el que enseña. La enseñanza lúdica es, comprobadamente por diversos autores, una estrategia positiva y eficaz para el aprendizaje infantil. La escuela debe resguardar de todas las formas el derecho de jugar a los niños, buscando la ludicidad natural del individuo. Se concluyó que los profesores no utilizan la enseñanza lúdica en el país en su real y total potencialidad, lo que corrobora negativamente para la enseñanza infantil en nuestro país.

Palabras clave: Lúdico. Educación. Enseñanza/aprendizaje

\section{INTRODUÇÃO}

A descoberta, o senso criativo e a obediência às regras são algumas das benesses proporcionados pelas brincadeiras. Tudo isso é ampliado quando introduzido e 
assimilando ao conteúdo desenvolvido em sala de aula, mas de forma natural, ou seja, sem modificar a convivência e o aprendizado que o aluno tem em seu ambiente escolar.

Este artigo busca trazer a temática do lúdico numa abordagem mais profunda, refletindo o seu impacto para crianças a partir de 5 anos de idade, e que fazem parte da rede de ensino infantil. A importância do lúdico, para elas, não é somente a atividade ou a brincadeira de forma liberta, prazerosa, mas o foco em sua aplicabilidade e conexão com os conteúdos dispostos na sala de aula também.

Por meio de pesquisa bibliográfica, onde cria-se uma reflexão analítica de diversos pontos de vistas diferentes sobre o mesmo tema, este trabalho tem por objetivo compreender e aprofundar o conceito de lúdico como uma estratégia para o desenvolvimento do ensino aprendizagem na área da educação. Dessa forma, busca-se entender como este conceito pode auxiliar diretamente no ensino dos alunos no ambiente escolar, bem como entender como ele pode facilitar a atuação do professor para que o processo de ensino/aprendizagem seja cada vez mais eficiente e prazeroso, tanto para o aluno quanto para aquele que leciona. $O$ ensino lúdico é, comprovadamente por diversos autores, uma estratégia positiva e eficaz para a aprendizagem infantil.

Dessa forma, o problema de pesquisa é retilíneo: os educadores estão realmente preparados para lidar com o ensino lúdico?

A hipótese é levantada com base na má gestão de recursos federais em capacitação e da falta didática na formação de professores no Brasil - um problema relativamente histórico, que percorre a década de 90, sob pesquisas de Santos (1997) e Piaget (1998) fazendo duras críticas aos cursos de licenciaturas, e, mais recentemente, com Lavoratti (2008) e Pereira (2005), que reforçam tal ponto de vista.

Ambos entendem que o ensino do lúdico é lento, afinal, não são só os recursos e a falta de didática que fazem parte dessas variáveis, mas também a ausência de iniciativas da coordenação escolar, a dificuldade dos profissionais em aliar as brincadeiras ao conteúdo teórico e, por fim, a falta de planejamento para que novas atividades atrativas sejam oferecidas aos alunos.

Assim, a hipótese é de que o lúdico não é trabalhado corretamente por motivos de força maior, que compete: a indefinição do próprio conceito de lúdico, a estrutura da escola, as representações políticas - que fazem o devido investimento na educação do país - e o não incentivo à inovação, seja por parte da coordenação ou dos próprios 
professores, que prejudica e dificulta o ensino/aprendizagem em todo o Brasil para os lecionandos e para os lecionados.

Entende-se, finalmente, que ainda há muitas barreiras a serem ultrapassadas para que o ensino lúdico seja efetivamente adotado e implementado nas escolas do ensino infantil.

\section{O DESENVOLVIMENTO LÚDICO NOS JOGOS}

Visto como um facilitador ou desenvolvedor de novas capacidades, o lúdico é um conceito ligado à dança, música e brincadeiras e jogos. Nestes últimos, o lúdico tem por finalidade trabalhar aspectos que maximizam e incluem novas formas de conhecimento (PASSOS, 2013). Ainda para o autor, trata-se de uma característica que transformam os jogos, simples ou complexos, em brincadeiras atraentes, participativas e altamente motivadoras, que nem sempre são particularidades vistas nos jogos e brincadeiras do tipo recreativo.

\subsection{O LÚDICO E O RECREATIVO}

Jogos recreativos - àqueles mais trabalhados nas séries infantis - têm por objetivo a diversão, o entretenimento, uma distração para os participantes. São muitas vezes competitivos, mas nem sempre são atribuídas metas. Tem como foco uma diversão momentânea, ligeira, fugaz (SANTOS, 2011).

Para Silva (2004), os jogos que visam o desenvolvimento do lúdico, por outro lado, jamais incentiva as competições, mas sim uma a resolução conjunta de problemas atípicos, criativos, novos, de modo que todos participem de forma arraigada, coletiva, sem perdedores ou ganhadores. É, em sua síntese, parecida com as competições, afinal, possui regras, número de participantes nas atividades e um objetivo principal. É, divergente em sua aplicação, no sentido de que há uma conquista coletiva, de caráter pedagógico, cultural e emocional.

Leon (2011), ensina que crianças que praticam jogos lúdicos, nesse sentido, se beneficiam de seus elementos: fomento à capacidade de resolver problemas novos, abertura propor suas próprias soluções, progressão física e mental, onde regras passam 
a ser manipuladas, fazendo progrida e desenvolva sua capacidade de se adaptar às mudanças.

\section{A REALIDADE EDUCACIONAL E O LÚDICO COMO PROCESSO DE APRENDIZAGEM}

Relacionando-se o conceito quanto a prática educativa, o lúdico apresenta duas concepções nos ensinamentos de Pereira (2005) e de Santos, Noccardo e Razera (2009) para os professores.

No primeiro, os professores podem buscar utilizar os jogos lúdicos como distração para os educandos. Nesta concepção, os jogos contentam os alunos diante de atividades mais pesadas e complicadas, tentando apaziguar o clima de dificuldade e insegurança. Na segunda concepção, utiliza-se o lúdico para ensinar novos conteúdos, independente do grau de dificuldade destes, oferecendo um sentido plausível para que este aluno aprenda o ensinamento.

Há, notavelmente, um distanciamento entre as duas concepções oferecidas por estes autores. Em relação à primeira, Cruz (2009) defende que o uso indiscriminado desta "estratégia" não traz a correta interpretação dos fatos aos alunos, afinal, não propõe uma situação que de fato pertence ao seu cotidiano. Neste caso, um jogo ou uma brincadeira não resolve ou apazigua uma situação de dificuldade, de objeção ou que oferece um grau de complexidade maior.

Para Gaspar (2011), diante da segunda concepção disposta, ela é válida, embora jogar por jogar dentro do ambiente de aprendizagem, sem que haja um objetivo prédefinido não é válido. Dessa forma, o lúdico deverá construir, associar ou atribuir conhecimentos diretamente relacionados com os conteúdos oferecidos em sala de aula para que traga resultados. O jogo, por si só, não possui valor educativo, mas a forma como é utilizado sim (AQUINO, 2005).

Ele deve contribuir no sentido de subtrair ou elevar um esforço intelectual (se esforçar menos para aprender mais, ou se esforçar mais para aprender mais), elevando o nível de atividades imprescindíveis para o aluno, como a leitura e a escrita, o suporte para compreensão da própria criança em relação ao espaço, tempo, movimentos corporais, senso crítico e criativo, dentre outros (BROUGÈRE, 2010). 
Para Leon (2011), o ensino lúdico também pode ser usado para o descanso como forma de entretenimento -, uma espécie de válvula de escape para conteúdos cansativos, que requerem um tempo de repouso maior. Pode ser considerada como uma terceira concepção para o seu uso, embora não seja bem quista pelo corpo científico atual, que resguarda a ideia da promoção do conceito do lúdico para promover e desenvolver conhecimentos, e não para entretenimento em momentos de descanso.

Percebe-se que são várias concepções sobre o lúdico como processo de aprendizagem na realidade educacional. Assim, segundo Silva (2009), o seu uso deve ser planejado com antecedência, direcionando sua implementação diante do objetivo que quer atingir. É inteiramente uma estratégia de ensino que, independente de sua concepção, busca fixar conceitos, elevar conhecimento e atribuir novas experiências e situações - o real conceito do termo lúdico.

O lecionando, neste cenário, precisa ter a aptidão necessária, ou seja, buscar mudanças e realizar uma autoanálise crítica de sua atuação, percebendo e reconhecendo seus pontos positivos e negativos, respectivamente (SILVA, 2004). Cabe, ao professor, ser o protagonista do seu próprio conhecimento. Ele deve estar sempre inovando, se tornando mais flexível para novas metodologias e, claro, resgatando e aprimorando conceitos.

Segundo Pereira (2005), é o ato de praticar o ensino lúdico com si mesmo, e ter o poder de aperfeiçoá-lo. Aperfeiçoar, aqui, significa intervir no nível de eficiência do ensino que ele pode propiciar aos seus alunos, baseando-se no quanto ele pode aprender consigo mesmo de maneiras totalmente novas. E quanto maior for o nível de eficiência ao transportar o lúdico também para o ambiente educacional, melhor será o nível de convivência com seus alunos, tornando ainda mais prazerosa sua profissão.

\footnotetext{
"A importância de viver o brincar como possibilidade de incorporação do lúdico à prática docente, na medida em que quanto mais o adulto vivenciar sua ludicidade, maior será a chance de este profissional trabalhar com a criança de forma prazerosa." (PEREIRA, 2005, p. 77).
}

A chave para isso, de acordo ainda com Pereira (2005), é o envolvimento. O envolvimento nos conteúdos exige, dos alunos, uma sedução pelo que lhes apresentado, no qual eles sempre irão buscar um significado do que estão e por que estão aprendendo; e, por parte dos professores, há a exigência do conhecimento, da habilidade em fazer com que os alunos compreendam enunciados e construam sua própria ciência. 
Acrescentando, Cruz (2009) explica que o envolvimento, por meio do lúdico, é muito mais difícil do que se apresenta na teoria. Isso ocorre porque os jogos têm por finalidade serem explorados pelos alunos das séries do ensino infantil, mas é o educador quem deve saber distinguir a hora certa de intervir na atividade e estimular uma nova visão, conceito ou reflexão da criança, explorando seu potencial de ideias, criação e imaginação. Além do momento certo, o educador também deve se atentar à idade e às necessidades de seus alunos, oferecendo os materiais adequados ao ensino lúdico, bem como a quantidade, a diversidade, ou qualquer outro recurso que favoreça seu desenvolvimento pleno (AQUINO, 2005).

As crianças brincam, se movimentam, observam e interagem com objetos, ou seja, são curiosidades por natureza. Cabe, ao educador, utilizar essa característica delas em seu favor, além de conhecer a personalidade de cada um de seus alunos, a fim de propor atividades diferenciadas para educandos diferenciados (GENTILE, 2008).

O lúdico, no momento em que a educação se encontra cada vez mais fragilizada, pode ser alcançado (PASSOS, 2013). O conhecimento é o maior recurso didático, tanto para o aluno quanto para seu professor, mas para que o conhecimento e o lúdico façam parte da rotina destes, deve haver um planejamento e intencionalidade por parte dos responsáveis pela gestão do ensino escolar, a começar pelo caráter competitivo que certas brincadeiras e jogos trazem. Por conta destes, os objetivos educacionais são esvaídos, dispersados.

Ainda para Passos (2013), dentre os cuidados ao implementar o lúdico na rotina da escola, os professores devem tomar cuidado com suas práticas, afinal, assumem a importante tarefa de conduzir o aprendizado, e não de apenas comunicar conhecimento.

\section{REFLEXÃO DO LÚDICO E SEU USO EDUCACIONAL}

Refletindo o conceito do lúdico nas literaturas que o trabalham, percebe-se uma natural diferença em sua definição. Alguns o associam aos jogos como uma atividade diferenciada, que deixa a aula mais atrativa, outros, apenas o associam às brincadeiras em sala de aula e, por fim, os que a entendem como uma estratégia para descanso em atividades pedagógicas mais cansativas. 
Segundo o Dicionário da Língua Portuguesa, o termo não fica explícito se o lúdico trata de jogos ou de brincadeiras, mas que ele é uma ação ou uma intervenção que gera a diversão, o entretenimento.

Se associado ao jogo, o termo lúdico pode perder um pouco seu teor, uma vez que, no Dicionário da Língua Portuguesa, a palavra jogo é definida como uma atividade física ou mental, normalmente coletiva, e que é provida de regras que definem ganhadores e perdedores - e a ideia de diversão passa a ser ausente, uma vez que quem perder não estará jamais satisfeito.

Mas, para o conceito científico, o lúdico, associado aos jogos ou às brincadeiras, é, modernamente, sustentado preceitos de Passos (2013), que enxerga o lúdico como um adjetivo à palavra "jogo", e que o jogo, em si, não possui um objetivo imediato ou definido previamente, apenas de provocar prazer e divertimento aos envolvidos. Nesse sentido, o autor extrai a ideia de que jogos promovem perdedores e ganhadores, fazendo com que o termo lúdico retome o sentido original a que é atribuído em aula.

Autores, como Santos (2011) e Carneiro (2012), explicam que os termos brinquedo, brincadeira, jogos e até divertimento não atrapalham, de alguma forma, no conceito do lúdico na educação - muito pelo contrário: eles o definem. As brincadeiras são a ação de brincar; o brinquedo é o objetivo designado para a ação; os jogos são as brincadeiras que envolvem regras e; 0 divertimento é o entretenimento propriamente dito e visto.

Para Gaspar (2011), independente dos termos, o conceito do lúdico sempre permanecerá atrelado aos jogos, pelo fato de que, com ou sem regras, com ou sem ganhadores ou perdedores, existe a disputa e a competição, o uso de habilidade físicas e mentais, a participação e o entretenimento - características despercebidas nas brincadeiras e nos brinquedos.

Observando tais pontuações, a elucidação de Brougère (2010) é a mais convincente e completa, que explica que o lúdico é apenas um objetivo diferente no processo/aprendizagem, que contempla aos professores a simples (e ao mesmo tempo complexa) tarefa de personalizar sua prática pedagógica em sala de aula, oferecendo aos alunos experiências e situações novas, abrindo preceitos para que estes últimos elevem o seu nível de conhecimento. 


\section{CONSIDERAÇÕES FINAIS}

São várias as visões e concepções acerca do lúdico. Há, de fato, mais interrogações do que certezas sobre seu real conceito, principalmente quando é analisada a origem ou as palavras ligadas ao termo, como jogos e brincadeiras.

Entende-se, portanto, que, ao deixarmos de lado a terminologia e refletirmos sobre a ação do lúdico nas brincadeiras e jogos por si só, perceberemos que há uma certa similaridade, afinal, desenvolve-se a comunicação efetiva, e as crianças ficam atentas e se divertem, e é por isso que alguns autores, inclusive, concluem que esse é o verdadeiro lúdico.

O lúdico, como levantado neste artigo, é também utilizado, além dos jogos e brincadeiras, nos conteúdos em sala de aula, como os exercícios, interpretação, leituras e na solução de problemas matemáticos, por exemplo. São manipulados, a fim de fomentar o desenvolvimento intelectual do aluno.

Já nos jogos - que remete sua verdadeira origem -, o lúdico é visto como uma estratégia isolada dos conteúdos, chamando a atenção dos alunos que estão muitas vezes dispersos às aulas com jogos e brincadeiras dissonantes ao conteúdo, e, dessa forma, o lúdico acaba se perdendo um pouco de sua verdadeira finalidade: desenvolver habilidades motoras e intelectuais, fixar os conteúdos da sala de maneira mais profunda, divertida e agradável, e permitir ao educador uma flexibilidade na construção e no direcionamento da aprendizagem, em um ambiente que remete ao criativo e ao não-explorado. Reforço: o lúdico não deve ser inserido na educação com a finalidade de distrair os educandos, afinal, isso limitaria seus benefícios e atingiria somente parte dos objetivos educacionais.

Ao contrário disso, deve ser visto, entendido e utilizado como um recurso didático, ou seja, estar além de jogos e brincadeiras, mas uma ferramenta que facilita a aprendizagem por parte do aluno, e que faz com que o professor possa refletir e questionar-se todos os dias sobre sua maneira de relacionar o conteúdo da matéria de forma mais prazerosa e eficiente.

A escola deve sim resguardar de todas as formas o direito de brincar das crianças, buscando a ludicidade natural do indivíduo. As brincadeiras devem ser vistas como o meio, direito e dever da criança; já as atividades lúdicas devem ser vistas como algo muito maior que isso tudo. Conclui-se que os professores não utilizam o ensino lúdico no país em sua real e total potencialidade - entendimento 
do conceito e implementação em sala de aula -, o que corrobora negativamente para o ensino infantil em nosso país.

\section{BIBLIOGRAFIAS}

AQUINO, J. G. (org.). Erro e fracasso na escola: alternativas teóricas e metodológicas. São Paulo: Summus, 2005.

BROUGÈRE, G. Brinquedo e Cultura. São Paulo: Cortez, 2010.

CARNEIRO, M. A. B. O brincar hoje: da colaboração ao individualismo. Simpósio Internacional da OMEP. Campo Grande, 2012.

CRUZ, J. de A. da. O lúdico como estratégia didática: investigando uma proposta para o ensino de física. In: Simpósio Nacional de Ensino de Física - SNEF, 18., 2009 - Vitória, Es. Anais... Vitória, Es. 2009. p. 1-8.

GASPAR, A. S. O lúdico na Educação Física Infantil. Trabalho de Conclusão de Curso (Graduação em Educação Física) - Universidade Estadual de Londrina, Londrina, 2011.

GENTILE, P. A Base da Sala de Aula. Nova Escola. São Paulo. Ano XXIII, N. 217, 2008.

LAVORATTI, L. Descompasso de Objetivos. Nova Escola. São Paulo. Ano XXIII, N. 217, p. 76 - 79, nov. 2008.

LEON, A. D. Reafirmando o lúdico como estratégia de superação das dificuldades de aprendizagem. In: Revista Organización de Estados Iberoamericanos para la Educación, la Ciência y la Cultura (OEI), Anais... SL, vol. 50, ํㅡ 56/3, p. 1-15, 2011.

PASSOS, M. P. de. $O$ ato lúdico de conhecer: a pesquisa como processo dialógico de apropriação de dispositivos informacionais e culturais. Dissertação (Mestrado em Ciência da Informação) - Escola de Comunicações e Artes, Universidade de São Paulo, São Paulo, 2013.

PEREIRA, J. E. A importância do lúdico na formação de educadores: uma pesquisa na ação do Museu da Educação e do Brinquedo - MEB. Tese (Doutorado em Educação) - Universidade de São Paulo, São Paulo, 2005.

PIAGET, J. A Psicologia da Criança. Rio de janeiro: Editora Bertrand Brasil, 1998.

SANTOS, S. M. P. dos (organizadora). O Lúdico na Formação do Educador. Petrópolis: Editora Vozes, 1997.

SANTOS, D R.; BOCCARDO, L.; RAZERA, J. C. C. Uma experiência lúdica no ensino de ciências sobre os insetos. In: Revista Organización de Estados Iberoamericanos para la Educación, la Ciência y la Cultura (OEI), Anais... SL, vol. 50, no 50/7, p. 1-3, 2009.

SANTOS, E. C. Dimensão lúdica e arquitetura: o exemplo de uma escola de educação infantil na cidade de Uberlândia. Tese (Doutorado em Ciências da Informação) - Faculdade de Arquitetura e Urbanismo, Universidade de São Paulo, São Paulo, 2011.

SILVA, A. M. T. B. da. O lúdico na relação ensino aprendizagem das ciências: resignificando a motivação. In: REUNIÃO ANUAL DA ANPED - Caxambu/MG. Anais... Caxambu, MG:

Psicologia da Educação, 2004.

Proposta de Ensino de Ciências sob forma lúdica e criativa nas escolas. In: Simpósio Nacional de Ensino de Física - SNEF, 18., 2009 - Vitória, Es. Anais... Vitória, Es. 2009.

XIMENES, S. Dicionário da Língua Portuguesa. 3. ed. Ver. E ampl. Sérgio Ximenes. São Paulo: Ediouro, 2000. 